\title{
FUENTES DE RESISTENCIA A LA ANTRACNOSIS Y LA MANCHA ANGULAR EN FRIJOL COMÚN PARA COSTA RICA ${ }^{1}$
}

\author{
Rodolfo Araya 2, Floribeth Mora ${ }^{3}$, Shree P. Shingh ${ }^{4}$
}

\begin{abstract}
RESUMEN
Fuentes de resistencia a la antracnosis y la mancha angular en frijol común para Costa Rica. El objetivo de este estudio fue la selección de fuentes de resistencia a la antracnosis y la mancha angular con base en material de diversa procedencia geográfica y con resistencias conocidas para estas enfermedades u otros factores bióticos o abióticos. Se evaluó en dos localidades (la Estación Experimental Fabio Baudrit Moreno y en la Sub-Estación Experimental Fraijanes, ambas de la Universidad de Costa Rica) un total de 173 materiales de frijol común: 46 cultivares criollos y 127 líneas mejoradas en 1996 y 1997. Se inoculó con una mezcla de cuatro razas (razas 9, 10, 547 y 1024 de mayor virulencia y cobertura en Costa Rica) del patógeno causante de antracnosis en cuatro ocasiones. Por la alta incidencia de mancha angular que se presenta naturalmente, la inoculación no fue necesaria. Se encontró 21 cultivares criollos y 13 líneas mejoradas con resistencia (nota de tres o menos) a la antracnosis. Solo cinco criollos (G 12529, G 14934, G 19428, G 19696, y G 19831), una cultivar mejorado (ICA Tundama), y la línea UCR 55, tuvieron reacción intermedia (nota entre cuatro y seis) a mancha angular. Se sugiere la evaluación de una gama más amplia de germoplasma de frijol común u otras especies relacionadas para la selección de resistencia a la mancha angular.
\end{abstract}

\begin{abstract}
Sources of resistance to anthracnose and angular leaf spot in common bean for Costa Rica. The objective of this study was to select sources of resistance to angular leaf spot and anthracnose from a diverse group of germplasm with known resistance to these diseases and other abiotic and biotic factors. A total of 173 common beans that included 46 landraces and 127 breeding lines were evaluated at two locations (Estación Experimental Fabio Baudrit Moreno and Sub-Estación Experimental Fraijanes, both of Universidad de Costa Rica) in 1996 and 1997. A mixture of four races (races 9, 10, 547, and 1024 of maximum virulence and coverage in Costa Rica) of the anthracnose pathogen was used to inoculate four times. Because of high natural incidence of angular leaf spot, inoculation was not necessary. Twenty-one landraces and 13 breeding lines were resistant (disease score of 3 or less) to antracnose. Only five landraces (G 12529, G 14934, G 19428, G 19696, and G 19831), one improved cultivar (ICA Tundama), and a breeding line UCR 55 had intermediate reaction (disease score between 4 and 6). Thus, for angular leaf spot evaluation of a much broader range of germplasm of common bean and other related species is suggested.
\end{abstract}

\section{INTRODUCCIÓN}

En Costa Rica, la antracnosis no se presentaba en zonas con una altitud inferior a los $500 \mathrm{msnm}$ en 1966 (Echandi, 1966), lo cual coincidía con el rango de temperatura a la que se inhibía esta enfermedad (Chaves, 1980). Desde finales de década de 1980, la incidencia de antracnosis se detectó en zonas frijoleras ubicadas a menos de $500 \mathrm{msnm}$, lo cual afectó las principales zonas comerciales de ésta leguminosa y fue la principal causa de rechazo de lotes de producción de semilla certificada (Araya, 1989). La causa de la amplia diseminación de la antracnosis en Costa Rica se atribuye al uso de semilla infectada (Araya, 1989).

1 Investigación financiada por la Universidad de Costa Rica, Vicerrectoría de Investigación y PROFRIJOL. Artículo número 99745 de la Estación Experimental de Agricultura de la Universidad de Idaho, Colegio de Agricultura, Moscow, ID 83844, EEUU.

2 Universidad de Costa Rica, Estación Experimental Fabio Baudrit Moreno. Apartado postal 183-4050 Alajuela, Costa Rica. Email: pccmca@sol.racsa.co.cr

3 Universidad Nacional, Laboratorio de Fitopatología. Apartado postal 86-3000. Heredia, Costa Rica.

4 University Of Idaho, 3793N 3600E, Kimberly, ID 83341-5076, U.S.A. E-mail: Shingh@kimberly.uidaho.edu (anteriormente con Centro Internacional de Agricultura Tropical, CIAT, A.A. 67-13, Cali, Colombia). 
Todos los cultivares liberados para uso comercial antes de 1990 son susceptibles a antracnosis debido a que el principal objetivo del programa de mejoramiento en Costa Rica fue la obtención de tolerancia a la mustia hilachosa causada por Thanatephorus cucumeris (Frank) Donk y arquitectura de la planta erecta para mecanización. El mayor daño se da en la Región Brunca, donde prevalece el uso de germoplasma criollo a nivel comercial y se emplea semilla producida artesanalmente obtenida de la cosecha comercial. En la Región Huetar Norte (principal zona frijolera del país) la incidencia de antracnosis es menor debido al empleo de semilla certificada y sólo una época de siembra. El cultivar Talamanca, el primero con tolerancia a la mustia hilachosa, fue eliminada del programa de certificación de semilla, debido a su alta susceptibilidad a la antracnosis. El primer cultivar liberado con resistencia a la antracnosis fue el Puricise (BAT 76), pero solo para uso en el Valle Central de Costa Rica. Posteriormente fue liberado el Chirripó Rojo (DOR 489), otro cultivar con resistencia a la antracnosis, pero mostró alta susceptibilidad a la mancha angular. Los restantes cultivares liberados en los últimos cuatro años, la Guamí (MUS 106) y la Maleku (RAB 572), son de alto potencial productivo pero son susceptibles a la antracnosis. Si se considera la amplia variabilidad Patogénica y agresividad de las razas causantes de antracnosis (Araya et al., 1991), la selección de fuentes de resistencia a este hongo es prioritaria para obtener cultivares estables en diferentes zonas productoras de frijol.

A finales de la década del 1970 no hubo evidencia de que la mancha angular pudiera ser determinante en la productividad del frijol y no se consideró como un carácter de importancia al evaluar germoplasma. Hasta 1977, se usó una estrategia de combate químico (González et al., 1977). En 1992, se efectuó otro estudio sobre el combate químico de la mancha angular (Hidalgo y Araya, 1993). La incidencia de mancha angular se hizo más intensa y dañina a partir de 1994, en que se informa de pérdidas de más del $50 \%$ por esta enfermedad. Todos los cultivares liberados para uso comercial, muestran susceptibilidad a mancha angular. La alta variabilidad de las razas de $P$. griseola y su mayor patogenicidad en América Central en relación con otras regiones, indica la importancia de este hongo a nivel comercial en esta región (Araya, 1999).

La necesidad de desarrollar cultivares de frijol con resistencia duradera a la antracnosis y la mancha angular nos motivó a iniciar este estudio. El objetivo fue evaluar germoplasma de diversos orígenes (y con importan- cia a otros factores limitantes de la producción) para identificar fuentes de resistencia a estas enfermedades.

\section{MATERIALES Y MÉTODOS}

Se evaluaron 173 materiales (46 cultivares criollos y 127 líneas mejoradas) procedentes de una selección efectuada en seis viveros en 1996 en la Estación Experimental Fabio Baudrit Moreno de la Universidad de Costa Rica, ubicada en Alajuela, Costa Rica, a $10^{\circ} 01$ de latitud norte y $84^{0} 16$ de longitud oeste a $840 \mathrm{msnm}$. Los viveros fueron (1) las líneas de frijol con adaptación a suelos de baja fertilidad y acidez, (2) líneas promisorias de frijol para bajo fósforo, (3) el CORE de frijol para bajo fósforo, (4) germoplasma criollo de Costa Rica, (5) fuentes de resistencia a la antracnosis (PastorCorrales et al., 1995), y (6) fuentes de resistencia a mancha angular (Pastor-Corrales et al., 1998) u otros factores bióticos y abióticos.

Las evaluaciones fueron realizadas entre septiembre de 1996 y diciembre de 1997. Se utilizaron las localidades de Alajuela (la Estación Experimental Fabio Baudrit Moreno) y Fraijanes (la Sub-Estación Experimental, ubicada a $10^{0} 09$ latitud norte y $84^{0} 12$ longitud oeste a $1850 \mathrm{msnm}$ ), ambos de la Universidad de Costa Rica. El tamaño de parcela fue de tres surcos de dos $\mathrm{m}$ de largo, tres surcos de seis $\mathrm{m}$ de largo, o cuatro surcos de cuatro $\mathrm{m}$ de largo sin repeticiones, dependiendo de la disponibilidad de semilla. La distancia entre surcos fue de $60 \mathrm{~cm}$ y se sembraron 15 semillas por metro lineal. En los dos sitios de evaluación no se protegió contra patógenos, no se utilizó fertilizantes, y sólo se adicionó Rhizobium phaseoli sobre la semilla al fondo del surco al momento de la siembra.

Se inoculó con una mezcla de las cuatro razas (razas 9, 10, 547 y 1024) de $C$. lindemuthianum más virulentas de Costa Rica. Fueron realizadas dos inoculaciones antes de floración y dos después de floración. Se utilizó una concentración de 1,2 x $10^{6}$ conidios por ml (Pastor-Corrales et al., 1994). La alta incidencia de mancha angular fue natural. Se utilizó una escala de uno a nueve, donde $1=\sin$ síntomas y $9=$ altamente susceptible (Schoonhoven y Pastor-Corrales, 1987) para evaluación de las plantas a la antracnosis y la mancha angular. Las evaluaciones se efectuaron a las seis y ocho semanas después de la inoculación, pero sólo se presenta en este artículo el valor más alto obtenido para ambas enfermedades en las dos localidades. Además, 
sólo se incluyen los materiales con reacción de uno a tres para antracnosis (i.e., los resistentes) y los de notas más bajos (seis o menos) para mancha angular.

\section{RESULTADOS Y DISCUSIÓN}

De un total de 173 cultivares criollos y líneas mejoradas de frijol evaluados, sólo 34 mostraron resistencia (grados de reacción entre 1 y 3 ) a la antracnosis (Cuadro 1). Entre ellos se encontraron 21 cultivares criollos (indicados con el código " $G$ " de banco de germoplasma del CIAT, Cali, Colombia) y 13 líneas o cul- tivares mejorados. Los 34 materiales con resistencia a la antracnosis varían en tamaño y color de semilla, hábito de crecimiento, y país de origen (Cuadro 1). Así también estos materiales pertenecen a diversas razas de frijol común (Shingh et al., 1991), lo que puede indicar posible variabilidad en sus genes de resistencia. Aunque no fue detectada una interacción entre patógeno y genotipo de frijol (por ser utilizadas una mezcla de las mismas cuatro razas de patógeno para inoculaciones en ambas localidades), Alajuela generalmente presentó notas más altas que los Fraijanes (datos no presentados). Esto puede sugerir que en el futuro si se utilizan inoculaciones con las misma razas deben concentrar las

Cuadro 1. Caracteres agronómicos y reacción de cultivares criollos (numero "G”) y líneas mejoradas de frijol común a la antracnosis y mancha angular en dos localidades (Alajuela y Fraijanes) de Costa Rica en 1996 y 1997.

\begin{tabular}{|c|c|c|c|c|c|c|}
\hline \multirow[b]{2}{*}{ Identificación } & \multicolumn{3}{|c|}{ Semilla } & \multirow[b]{2}{*}{ Habito $^{1}$} & \multirow[b]{2}{*}{ Antracnosis ${ }^{2}$} & \multirow{2}{*}{$\begin{array}{l}\text { Mancha } \\
\text { Angular }\end{array}$} \\
\hline & Origen & Color & Tamaño & & & \\
\hline \multicolumn{7}{|c|}{ Cultivares criollos } \\
\hline G 01368 & Honduras & Rojo & Pequeño & III & 2 & 8 \\
\hline G 02241 & & & & & 2 & 8 \\
\hline G 03624 & & & & & 3 & 8 \\
\hline G 04672 & Colombia & Amarillo & Pequeño & III & 2 & 7 \\
\hline G 09855 & Ecuador & Amarillo & Grande & III & 3 & 8 \\
\hline G 10843 & Guatemala & Negro & Pequeño & IV & 2 & 7 \\
\hline G 11564 & & & & & 3 & 8 \\
\hline G 12484 & & Rosado/rojo & Mediano & III & 3 & 8 \\
\hline G 12529 & Perú & Rojo & Mediano & III & 2 & 6 \\
\hline G 13755 & & & & & 3 & 8 \\
\hline G 14861 & México & Negro & Pequeño & IV & 2 & 8 \\
\hline G 14934 & Brasil & Crema & Mediano & IV & 2 & 6 \\
\hline G 15317A & Zambia & Rojo & Mediano & III & 3 & 8 \\
\hline G 16270 & Honduras & Negro & Pequeño & III & 2 & 7 \\
\hline G 16400 & México & Café marrón/negro & Pequeño & IV & 3 & 8 \\
\hline G 19428 & Perú & Rosado/comb & Grande & III & 2 & 4 \\
\hline G 19696 & Perú & Rosado/amarillo & Grande & IV & 2 & 6 \\
\hline G 19831 & Perú & Rojo/rosado & Pequeño & III & 2 & 6 \\
\hline G 19860 & Perú & Morado/crema & Grande & III & 3 & 7 \\
\hline G 20755 & & & & & 2 & 7 \\
\hline G 22317 A & & & & & 3 & 8 \\
\hline
\end{tabular}

Líneas o cultivares mejorados

\begin{tabular}{|c|c|c|c|c|c|c|}
\hline A 36 & CIAT & Rojo moteado & Mediano & II & 2 & 7 \\
\hline A 83 & CIAT & Crema rayado & Pequeño & III & 3 & 7 \\
\hline A 193 & CIAT & Rojo moteado & Pequeño & II & 3 & 7 \\
\hline A 483 & CIAT & Morado/moteado & Mediano & III & & \\
\hline AND 277 & CIAT & Rojo moteado & Grande & I & 3 & 8 \\
\hline BAC 50 & Brasil & Rojo & Mediano & II & 3 & 8 \\
\hline Bayo 107 & México & Bayo & Mediano & III & 3 & 8 \\
\hline Bayo 400 & México & Bayo & Mediano & III & 3 & 9 \\
\hline DIACOL Calima & Colombia & Rojo moteado & Grande & I & 3 & 7 \\
\hline ICA Tundama & Colombia & Rojo moteado & Grande & II & 2 & 6 \\
\hline K 2 & EEUU & Café & Grande & I & 3 & 8 \\
\hline Manzano & México & Morado & Mediano & III & 3 & 8 \\
\hline RAS 59 & & & & & 2 & 7 \\
\hline TF 9223 & & & & & 2 & 7 \\
\hline UCR 55 & Costa Rica & Negro & Pequeño & II & - & 5 \\
\hline
\end{tabular}

${ }^{1}$ Habito I= determinado arbustivo; $\mathrm{II}=$ indeterminado arbustivo, $\mathrm{III}=$ indeterminado postrado, y IV= indeterminado trepador agresivo.

2 Scala de evaluación $1=\sin$ síntomas y 9= altamente susceptible; también clasificado 1 a 3 como resistente, 4 a 6 intermedio, y 7 a 9 susceptible. 
evaluaciones (por lo menos en etapas iniciales) en la localidad de Alajuela, así ahorrando recursos y tiempo.

El número de materiales y grado de resistencia encontrada para mancha angular fue muy bajo (Cuadro 1). El único material, G 19428, con nota más baja tuvo resistencia intermedia (grado 4). Otros cinco materiales (G 12529, G 14934, G 19696, G 19831 y ICA Tundama) tuvieron notas de 6. SCHWARTZ et al. (1982) y Pastor-Corrales et al. $(1995,1998)$ también encontraron relativamente pocos materiales resistentes a mancha angular en comparación a antracnosis. Esto indica un gran reto en y la necesidad de la búsqueda continua de nuevas fuentes de resistencia a este enfermedad tan importante no únicamente en Costa Rica si también para el resto de América Latina u otras partes del mundo. Sería a aconsejable buscar resistencia también en acervo secundario (P. costaricensis, $P$. coccineus, y P. polyanthus) y terciario (P. acutifolius y P. parvifolius) de frijol común. Además debe notarse que del total de materiales seleccionados por su resistencia a la antracnosis, el $62 \%$ correspondió a materiales procedentes de germoplasma. Así igualmente para mancha angular cinco de los seis materiales con nota más baja (reacción intermedia de resistencia) fueron cultivares criollos obtenidos del banco de germoplasma, lo que viene a reafirmar la importancia de continuar con las colectas, conservación, rescate y evaluación del germoplasma de frijol en América Latina para la selección de nuevas fuentes de resistencia a la antracnosis, mancha angular, u otros factores abióticos y bióticos limitantes. Con base en lo indicado por Debouck (1999) sobre existencia de germoplasma de frijol y otras especies en banco de germoplasma y por Shingh (1992) sobre el uso de menos del $5 \%$ del germoplasma de frijol en la mejora genética del frijol a nivel mundial, queda mucha variabilidad genética por evaluar y utilizar. La estrategia de hibridación y producción de cruzamientos de padres múltiples (Shingh, 1998) también podría facilitar aprovechamiento de germoplasma para piramidación de los genes de resistencia de diferentes orígenes, lo cual traería una mayor estabilidad de la resistencia a nivel de los pequeños agricultores y comercial.

El conocimiento de la existencia de dos grandes grupos en patógenos causantes de la antracnosis (Balardin y Kelly, 1998; Balardin et al., 1997; Pastor-Corrales et al., 1995) y mancha angular (Guzmán et al., 1995; Pastor-Corrales y Jara, 1995; Pastor-Corrales et al., 1998) y una relación estrecha entre ellos y los dos acervos genéticos Andino y Mesoamericano de frijol (Gepts y Bliss, 1985; Khairallah et al., 1990; Shingh et al., 1991) debe ser considerado seriamente en la búsqueda de nuevas fuentes de resistencia para estas enfermedades para cada región geográfica. Lo mismo debe tomarse en cuenta para piramidación de los genes útiles para conseguir una resistencia adecuada y duradera (Shingh, 1992, 1999). En el caso específico de Costa Rica, la procedencia andina de la mayoría de los materiales resistentes identificados para ambas enfermedades confirma lo indicado sobre la ventaja de estos materiales en relación con los mesoamericanos, por efectos de coevolución patógeno-hospedero. Además, estos materiales se habían identificado por su resistencia o tolerancia a otros factores, lo que amplía su aporte dentro de una estrategia de mejoramiento por hibridación.

\section{AGRADECIMIENTOS}

Se agradece al Dr Rogelio Lépiz, Coordinador del Programa Cooperativo Regional de Frijol para Centroamérica, México y El Caribe (PROFRIJOL) y al Dr Carlos Araya, Laboratorio de Fitopatología de la Universidad Nacional, Costa Rica, por la colaboración brindada en evaluaciones de campo.

\section{LITERATURA CITADA}

ARAYA , C. M. 1989. La antracnosis del frijol (Phaseolus vulgaris L.) en Costa Rica. Manejo integrado de plagas (C. R.). 13: 83-89.

ARAYA, C.M. 1999. El cultivo del frijol en Costa Rica: una propuesta de integración nacional para el manejo sostenible de sus principales enfermedades. Manejo integrado de plagas (C. R.).(MIP) (en prensa).

ARAYA, C.M.; PASTOR CORRALES M.A.; RAMÍREZ J.F. 1991. Variación patogénica de aislamientos de Colletotrichum lindemuthianum de frijol procedentes de la zona noreste y central de Costa Rica. Agronomía Costarricense 15(1-2): 63-66.

BALARDIN, R.S.; JAROSZ A.M.; KELLY J.D. 1997. Virulence and molecular diversity in Colletotrichum lindemuthianum from South, Central and North America. Phytopathology 87:1184-1191.

BALARDIN, R.S.; KELLY J.D. 1998. Interaction between races of Colletotrichum lindemuthianum and gene pool diversity in Phaseolus vulgaris. J. Amer. Soc. Hort. Sci. 123:1038-1047.

CHAVES, G. 1980. La antracnosis. In. Schwartz, H.F. y Galvez G. (Ed). Problemas de producción de frijol: enfermedades, insectos, limitaciones edaficas y climáticas de Phaseolus vulgaris. CIAT, Cali, Colombia. pp.37-53. 
DEBOUCK, D.G. 1999. Diversity in Phaseolus species in relation to the common bean. In SINGH, S.P. (ED) Common bean improvement in the twenty-first century. Kluwer, Dordrecht, Netherlands. pp.25-52.

ECHANDI, E. 1966. Principales enfermedades del frijol observadas en diferentes zonas ecológicas de Costa Rica. Turrialba 14 (4): 359-363.

GEPTS, P.; BLISS F.A. 1985. F1 hybrid weakness in the common bean: differential geographic origin suggests two gene pools in cultivated bean germplasm. J. Hered. 76:447-450.

GONZÁLEZ, L.C.; GUTIÉRREZ R.; CASCANTE F. 1977. Combate de enfermedades foliares en frijol (Phaseolus vulgaris L.) mediante el uso limitado de fungicidas. Agronomía Costarricense 1 (2): 107-118.

GUZMÁN, P.; GILBERTSON R.L.; NODARI R.; JOHNSON W.C.; TEMPLE S.R.; MANDELA D.; MKANDAWIRE A.B.C.; GEPTS P. 1995. Characterization of variability in the fungus Phaeoisariopsis griseola suggests coevolution with the common bean (Phaseolus vulgaris). Phytopathology 85:600-607.

HIDALGO, R.; ARAYA C.M. 1993. Estado de crecimiento óptimo del frijol común para el combate químico de antracnosis (Colletotrichum lindemuthianum) y mancha angular (Isariopsis griseola) en San Carlos, Costa Rica. Agronomía Costarricense 17(1): 75-80.

KHAIRALLAH, M.M.; ADAMS, M.W.; SEARS B.B. 1990. Mitochondrial DNA polymorphisms of Malawian bean lines: further evidence for tow major gene pools. Theo. Appl. Genet. 80:753-761.

PASTOR-CORRALES, M.A.; ERAZO O.A.; ESTRADA E.I.; SINGH S.P. 1994. Inheritance of anthracnose resistance in common bean accession G 2333. Plant Dis. 78:959-962.

PASTOR-CORRALES, M.A.; JARA C.A. 1995. La evolución de Phaeoisariopsis griseola con el frijol común en América Latina. Fitopatol. Col. 19(1):15-24.
PASTOR-CORRALES, M.A.; JARA C.; SINGH S.P. 1998. Pathogenic variation in, sources of, and breeding for resistance to Phaeoisariopsis griseola causing angular leaf spot in common bean. Euphytica 103:161-171.

PASTOR-CORRALES, M.A.; OTOYA M.M.; MOLINA A.; SINGH S.P. 1995. Resistance to Colletotrichum lindemuthianum isolates from Middle America and Andean South America in different common bean races. Plant Dis. 79:63-67.

SCHOONHOVEN, A. VAN; PASTOR-CORRALES M.A. (comps.). 1987. Sistema estándar de evaluación de germoplasma de frijol. CIAT, Cali, Colombia. 56p.

SCHWARTZ, H.F.; PASTOR-CORRALES M.A.; SINGH S.P. 1982. New sources of resistance to anthracnose and angular leaf spot of beans (Phaseolus vulgaris L.). Euphytica 31: 741-754.

SINGH, S.P. 1992. Common bean improvement in the tropics. Plant Breed. Rev. 10:199-269.

SINGH, S.P. 1998. Uso de marcadores y selección de gametos para el mejoramiento simultáneo de caracteres múltiples de frijol (Phaseolus vulgaris L.) para Mesoamérica y El Caribe. Agronomía Mesoamericana (C.R.) 9 (1): $1-9$.

SINGH, S.P. 1999. Integrated genetic improvement. In Singh, S.P. (ED.) Common bean improvement in the twenty-first century. Kluwer, Dordrecht, Netherlands. p.133-165.

SINGH, S.P.; GEPTS P.; DEBOUCK D.G. 1991a. Races of common bean (Phaseolus vulgaris Fabaceae). Econ. Bot. 45:379-396.

SINGH, S.P.; GUTIÉRREZ J.A.; MOLINA A.; URREA C.; GEPTS P. 1991b. Genetic diversity in cultivated common bean: II. Marker-based analysis of morphological and agronomic traits. Crop Sci. 31:23-29. 